\title{
Land Suitability Evaluation for Cassava Production Using Integral Value Ranked Fuzzy AHP and GIS Techniques
}

\author{
Atijosan Abimbola ${ }^{1}$, Essien Ewang ${ }^{2}$, Badru Rahmon $^{3}$ and Alaga Taofeek ${ }^{4}$ \\ ${ }^{1,3,4}$ COPINE (Advanced Space Application Laboratory),Obafemi Awolowo University \\ Campus, Ile-Ife, Nigeria \\ ${ }^{2}$ Centre for Satellite Technology Development,Obasanjo Space Centre, Abuja, \\ Nigeria \\ 1bimbo06wole@yahoo.com, 22ewang_arcsste@yahoo.com, ${ }^{3}$ sunkanmi@yahoo.com, \\ ${ }^{4}$ alagayomi@yahoo.com
}

\begin{abstract}
This study presents an improved integral value ranked Fuzzy Analytic Hierarchy Process (FAHP) and Geographic Information System (GIS) based Multi-Criteria Decision Making (MCDM) technique to help decision-makers/farmers evaluate and map suitable lands for optimum cassava production. Selected input/ suitability factors chosen from literature and experts' opinion were: $p H$, organic carbon, cation exchange capacity, slope, aspect, elevation, temperature, relative humidity, rain, distance from river and road. The improved integral value ranked FAHP method was used in prioritizing and assigning weights to each causative factor in the MCDM process due to its effectiveness, consistency, and ease of implementation. Land suitability maps were created using GIS techniques based on the aggregation of the various input factors and their derived weights. The outcome of the aggregation was reclassified into four classes using the standard deviation classification method (this method shows how much a feature deviates from the mean). Results obtained showed that $40 \%$ of the total area was highly suitable (S1), 36\% was moderate suitability (S2), 20\% was marginally suitable (S3) and 4\% was not suitable (N). Results also showed that $\mathrm{pH}$ and organic content of the soil were the major determinants of soil suitability for cassava cultivation in the study area. This study showed the effectiveness of the proposed approach in assessing and mapping suitable areas for optimum cassava production within the study area.
\end{abstract}

Keywords: Land suitability, Cassava, PSO, GIS, Multi-criteria decision

\section{Introduction}

Effective decision-making based on land suitability evaluation for agricultural crop selection is crucial to achieving optimum land productivity and ensuring environmental sustainability [1]. Land evaluation is concerned with the process of determining the optimal use potential of land for a specific purpose based on its attributes [2]. As a core element of land use planning, land resource evaluation is central at all stages of planning and implementation [3][4]. As it guides decision-makers in attempting to select appropriate types of land use, determining best spatial locations of planned agricultural activity, identifying opportunities for land use change

Article history:

Received (November 9, 2020), Review Result (December 12, 2020), Accepted (January 16, 2021)

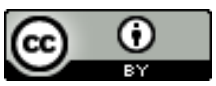

() 2021 Atijosan Abimbola, Essien Ewang, Badru Rahmon and Alaga Taofeek. Published by Global Vision Press

This is an open access article distributed under the terms of the Creative Commons Attribution License (CC BY4.0), which permits unrestricted use, distribution, and reproduction in any medium, provided the original author and source are credited. 
and the outcomes of changing land use policies [3][4] Land suitability evaluation is essential for production planning and the sustainable use of land over time [5]. Furthermore, it provides information on the potentials and constraints of land for a defined land use type for optimum crop performance [5].

In many counties of Sub-Saharan Africa, cassava (Manihot esculenta Crantz) is a major source of food [6][7]. It is a key income generating and food security crop in Africa [7][8]. Furthermore, cassava is widely used as a suitable feedstock for ethanol production [9]. It has also been identified that cassava-based fuel ethanol is an excellent alternative for petroleumbased fuels due to the inherent positive energy balance and fossil energy savings [10]. To enhance cassava production, appropriate areas and ecological conditions must be earmarked [11]. This can be accomplished through effective land use suitability evaluations using spatial multicriteria decision-making techniques.

Integrating GIS with MCDM techniques can help land-use planners improve decisionmaking processes [12]. Analytical Hierarchy Process (AHP) technique is one of the most popularly used MCDM techniques in GIS-based suitability evaluation procedures [13] due to its appropriateness for decision making based on multiple factors ranked according to experts' predilections [14]. Integrating AHP with fuzzy set theory provides more robustness and accuracy as fuzzy set theories use advanced procedures to handle imprecise, uncertain, or vague data arising from real life problems which are complex and nonlinear [15][16][17]. Together, multi-criteria decision-making methods integrating AHP with fuzzy logic, create an effective and suitable technique for optimum agricultural land suitability evaluations and have thus found wide applications for such [14][18][19].

Prioritizing and weight assignment to each criterion concerning a set of existing alternatives is key to effective decision making in any MCDM process [20] including land suitability evaluations for cassava production [19]. From literature, various techniques have been proposed which prioritize, rank, and assign weights to the available criteria based on comparison ratios represented by fuzzy numbers [20]. The most popular among these techniques is the fuzzy extent analysis method [21], with modifications by other researchers such as [20]; others include the fuzzy preference programming method [22], the integral value rank method by [23], and the improved integral value rank method by [24]. Compared with the extent analysis method, the integral value ranked fuzzy AHP approach is a more effective way to rank and prioritize fuzzy numbers [25][26][27]. Despite its positive sides, it suffers from some shortcomings such as the inability to differentiate normal and non-normal fuzzy numbers, and occasional inconsistency in ranking fuzzy numbers [24]. The improved integral value rank approach by [24], overcomes these shortcomings, thus improving accuracy on assigned weights.

This study presents an improved integral value ranked fuzzy AHP and GIS based MCDM approach to evaluate land suitability and map out suitable areas for cassava production in the study area. This is to identify areas most suitable for cassava production thus, ensuring sustainable and optimum cassava production within the study area.

\section{Materials and methods}

\subsection{Study Area}

The study area is located in Ife Central Local Government Area in Osun State, Southwestern Nigeria. It lies between latitudes $7^{\circ} 28^{\prime} 43.5^{\prime}$ ' $\mathrm{N}$ and $7^{\circ} 37^{\prime} 51.41^{\prime}$ ' $\mathrm{N}$ and spans between longitude $4^{\circ} 27^{\prime} 22.5^{\prime}$ ' $\mathrm{E}$ and $435^{\prime} 40.61^{\prime}$ 'E. [Figure 1], illustrates the map of the study area. 


\subsection{Selection of factors for suitability analysis}

Input factors used were: $\mathrm{pH}$, Organic Carbon (OC), Cation Exchange Capacity (CEC), slope, aspect, elevation, temperature, Relative Humidity (RH), rain, Distance from River (DFRi) and Distance from Road (DFRo). Choice of criteria was identified from within relevant literature and experts' opinions. Details are given in this section. [Table 1] highlights data source, category, and description.

Table 1. List of data and data sources use for land

\begin{tabular}{|c|c|c|c|c|}
\hline No & Category & Data & Description & Source \\
\hline 1 & Soil properties & $\mathrm{pH}$ & $15 \mathrm{~cm}$ depth & ISRIC (soilgrid.org) \\
\hline 2 & Soil properties & OC & $15 \mathrm{~cm}$ depth & ISRIC (soilgrid.org) \\
\hline 3 & Soil properties & CEC & $15 \mathrm{~cm}$ depth & ISRIC (soilgrid.org) \\
\hline 4 & Topography & Slope & $30 \mathrm{~m}$ resolution & 2017 ASTER DEM \\
\hline 5 & Topography & Aspect & $30 \mathrm{~m}$ resolution & 2017 ASTER DEM \\
\hline 6 & Topography & Elevation & $30 \mathrm{~m}$ resolution & 2017 ASTER DEM \\
\hline 7 & Metrology & Temperature & $0.5 x 0.5$-degree resolution & CDG (edataguide.ucar.edu) \\
\hline 8 & Metrology & RH & $0.5 x 0.5$-degree resolution & CDG (edataguide.ucar.edu) \\
\hline 9 & Metrology & Rain & Predicted precipitation & IPPC5 (CMIP5) data \\
\hline 10 & Accessibility & DTRi & Digitized from image & 2019 Google earth image \\
\hline 11 & Accessibility & DTRo & Digitized from image & 2019 Google earth image \\
\hline
\end{tabular}

(1) Soil $\mathrm{pH}$ plays a vital role in the biological activity of the soil and the availability of mineral nitrogen to plants. It can influence the efficiency of plant growth in the soil [28]. Data was obtained from ISRIS Soilgrid dataset [29].

(2) Soil Organic Carbon: Low organic carbon is a serious restraint to effective cassava cultivation and production [30]. Data was obtained from ISRIS Soilgrid dataset [29].

(3) Cation Exchange Capacity: CEC is vital for cassava tuber growth as it positively and significantly correlates with tuber yield [31]. Data was obtained from ISRIS Soilgrid dataset [29].

(4) Elevation plays a key role in the production of energy crops like cassava. [9][32]. The elevation data used was obtained from the advanced spaceborne thermal emission and reflection radiometer (ASTER) global digital elevation model (DEM) with a resolution of $30 \mathrm{~m}$.

(5) Aspect of slope position has a direct correlation with cassava yield [33]. This was obtained from DEM used for elevation.

(6) Slope: Topography plays a vital role in the growth of vegetation, for example, soil and water are easily lost inland with a steep slope, which is not beneficial to the growth of cassava [9]. A slope map was obtained from the DEM used for elevation.

(7) Temperature is a critical factor for the growth of cassava as it influences both the metabolism of cassava plants and the life cycle, which directly determines the final yield of cassava [9]. Data was obtained from the climate data guide dataset [34].

(8) Relative humidity is positively correlated with the yield of Cassava [35]. Data was obtained from the climate data guide dataset [34].

(9) Rainfall is an important factor as it plays a crucial role in determining the yield of the cassava crop [9]. Based on the availability of data, predicted precipitation was used in this study. It was obtained from the downscaled IPPC5 (CMIP5) data using global climate model (GSM) CCSM4 under scenario Representative Concentration Pathway (RCP) 6. 
(10) Distance from rivers. Distance from rivers was obtained by digitizing rivers from high resolution images $(0.4 \mathrm{~m})$ obtained from Google Earth imagery. Thereafter four buffers at intervals of 350 meters were used to determine distance from rivers.

(11) Distance from roads. In selecting suitable areas for cassava cultivation, the distance from roads must be considered because distance affects transportation cost [19]. Road network was obtained by digitizing major roads from high resolution images $(0.4 \mathrm{~m})$ obtained from Google Earth imagery.

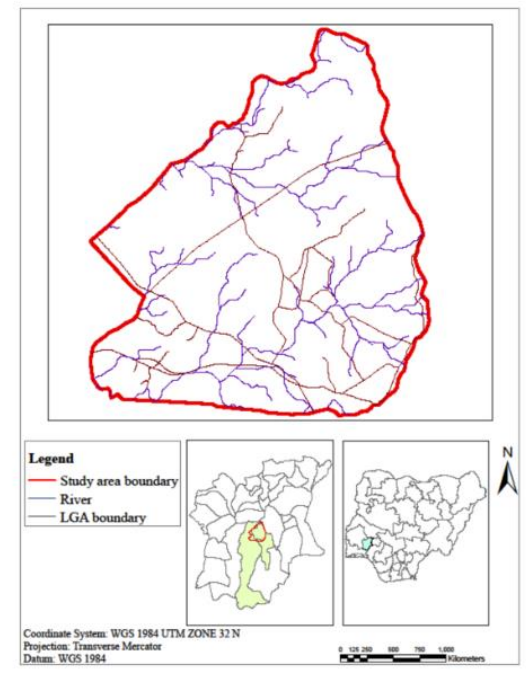

Figure 1. Study area map

\subsection{Reclassification of criteria}

Reclassification was carried out using the natural breaks (Jenks) classification method (this method is founded on natural groupings intrinsic in the data). Each of the criteria source map [Figure 2.a-f] was reclassified into four classes: highly suitable (S1), moderately suitable (S2), marginally suitable (S3), and not suitable $(\mathrm{N})$ [Figure 3.g-k]. Reclassification was used to group ranges of values in each of the criteria source maps into single values among the four classes (S1, S2, S3, and S4).

\subsection{Establishing decision hierarchy}

A three-level decision hierarchy structure as shown in figure 4 was adopted. The hierarchy consists of the main objective at the top (Land suitability), followed by two levels of hierarchy. The eleven factors used in this research were divided into four main groups; soil properties, topography, metrology, and accessibility factors, to form the second hierarchy. The third hierarchy consists of eleven factors of which three were soil properties $(\mathrm{pH}, \mathrm{OC}$, and CEC), three were topography (aspect, slope, and elevation), three meteorology (temperature, relative humidity, and rain), and two accessibility (distance from river and distance from road). The study area boundary was used as a constraint factor. The examined factors and decision hierarchy were selected based on literature [9][19][28][32]. 


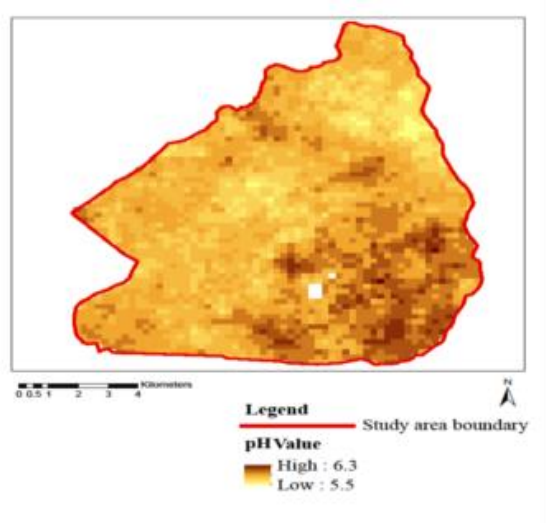

(a) $\mathrm{pH}$

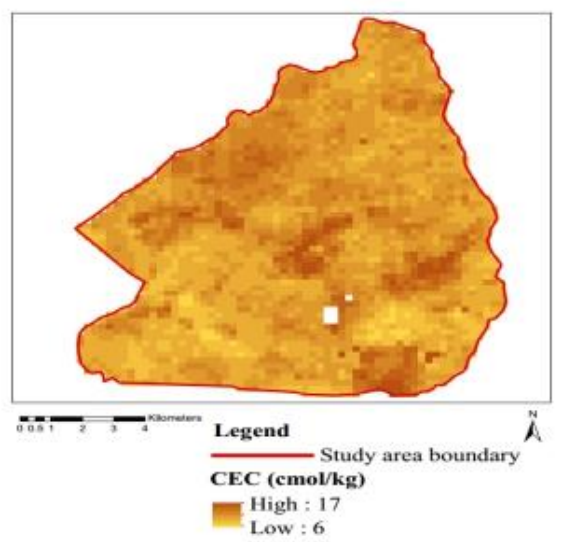

(c) CEC

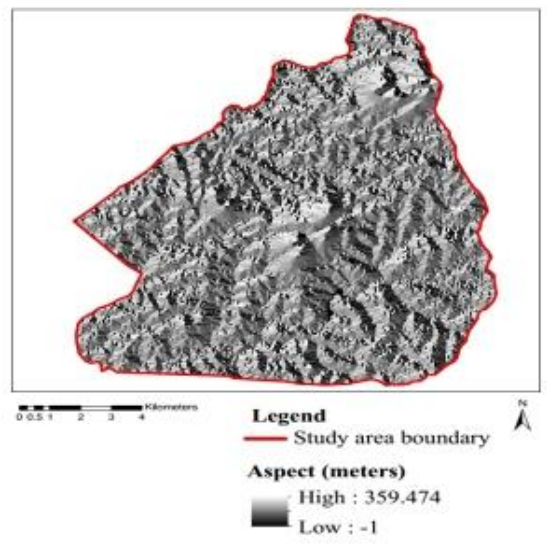

(e) Aspect

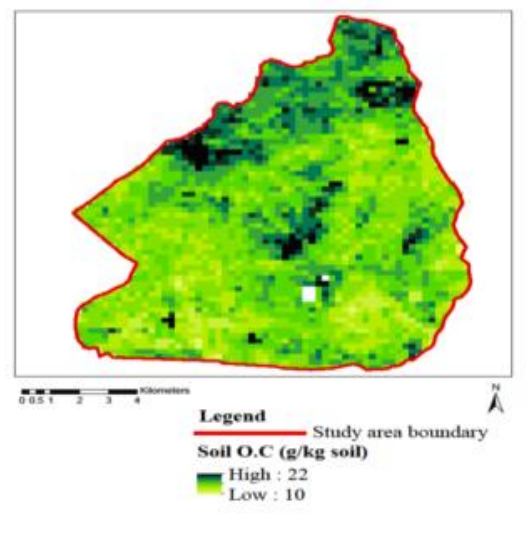

(b) Soil OC

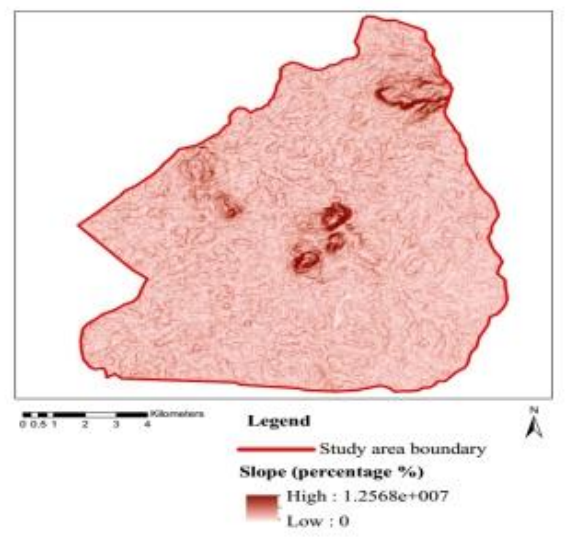

(d) Slope

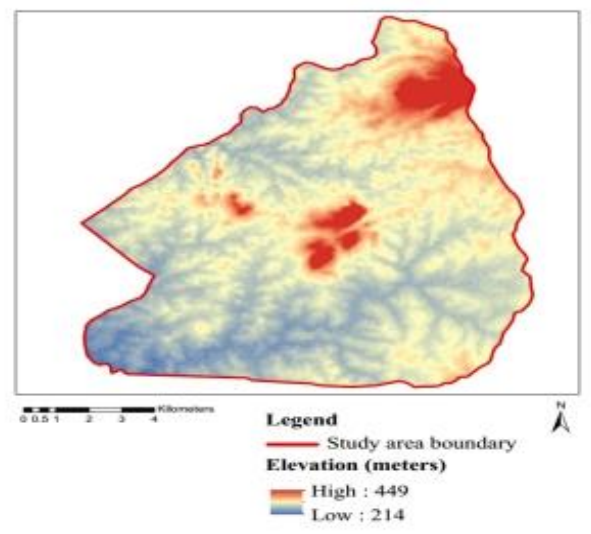

(f) Elevation

Figure 2. (a-f) Criteria for land suitability analysis 
Land Suitability Evaluation for Cassava Production Using Integral Value Ranked Fuzzy AHP and GIS Techniques

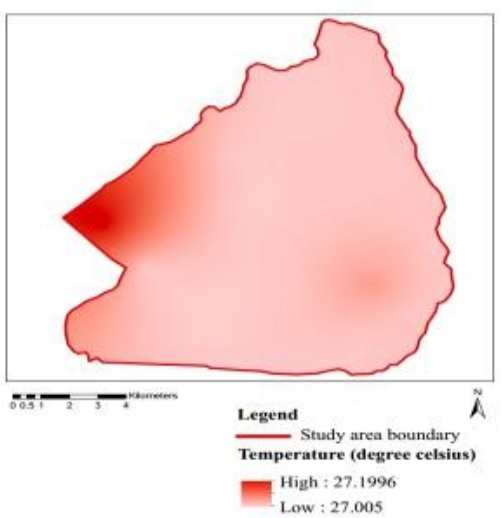

(g) Temperature

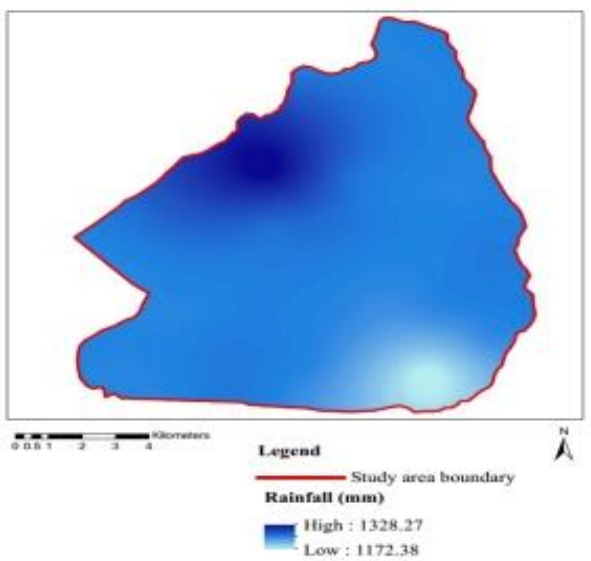

(i) Rainfall

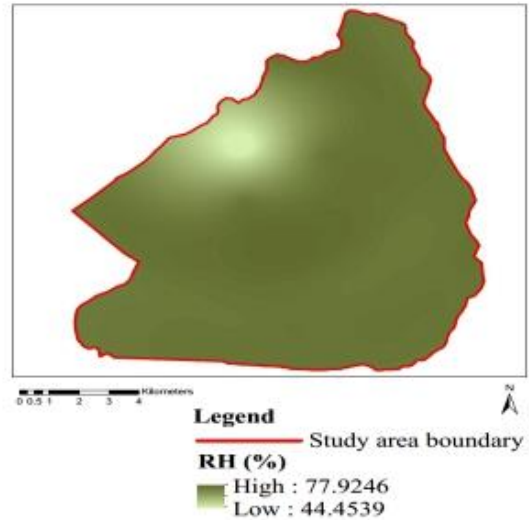

(h) Relative humidity

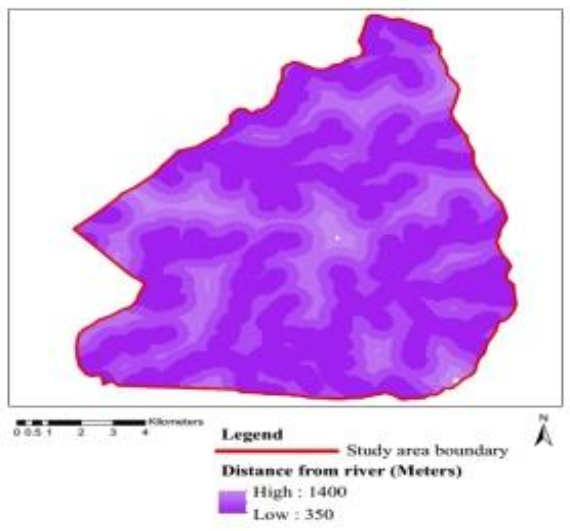

(j) Distance from rivers

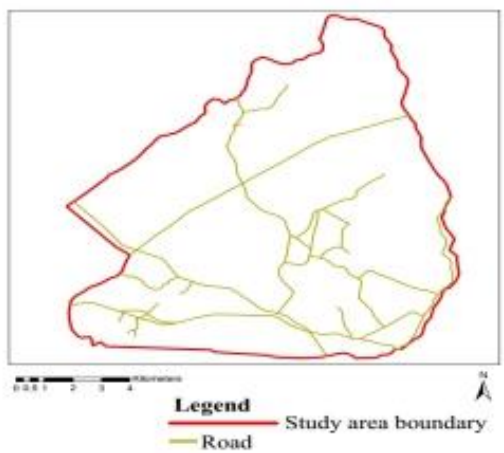

(k) Road

Figure 3. (g-k) Criteria for land suitability analysis 


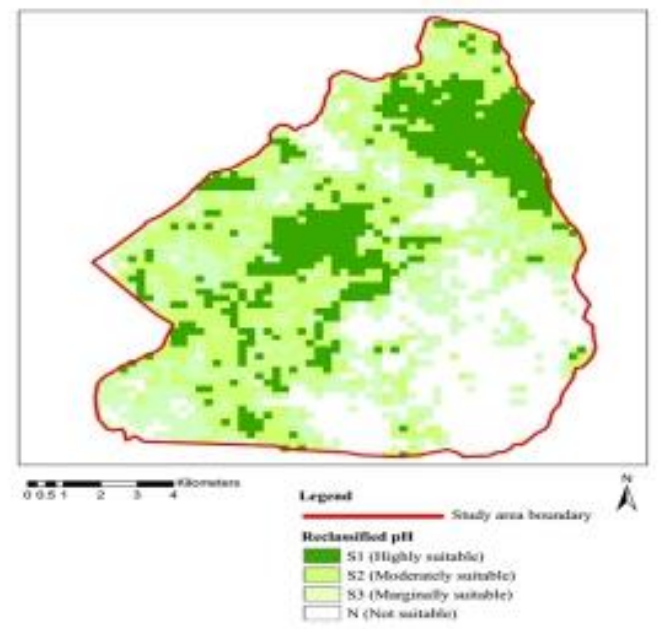

(a) Reclassified $\mathrm{pH}$

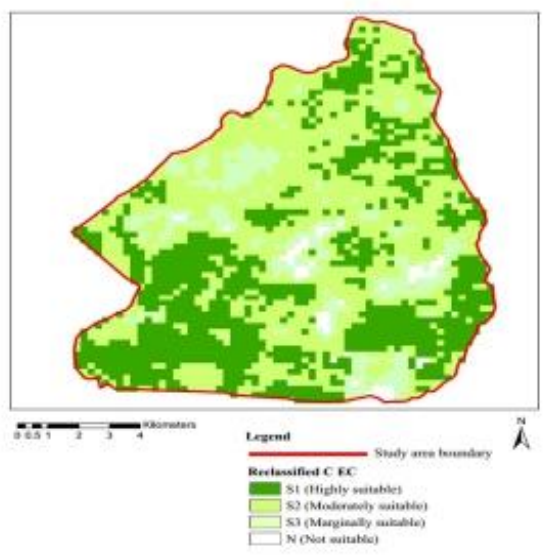

(c) Reclassified CEC

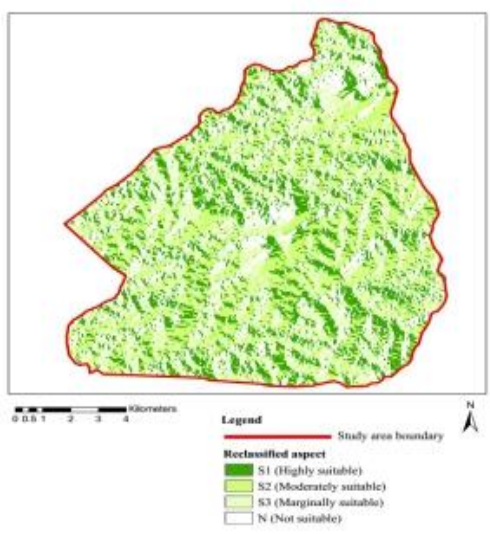

(e) Reclassified Aspect

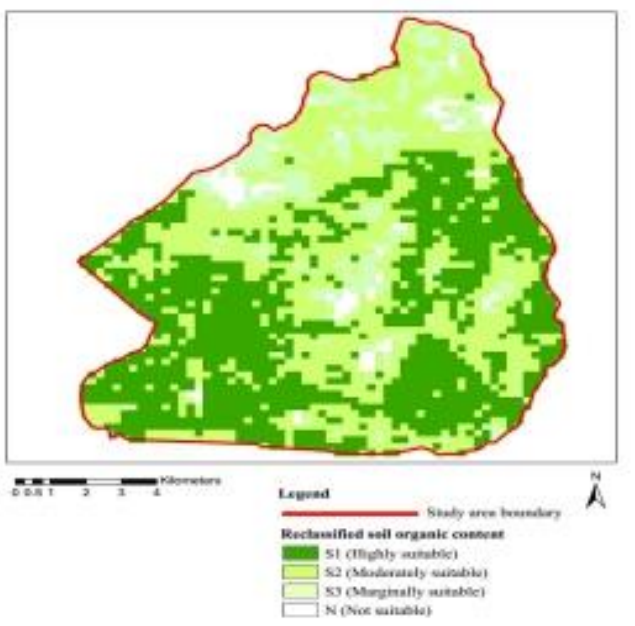

(b) Reclassified Soil OC

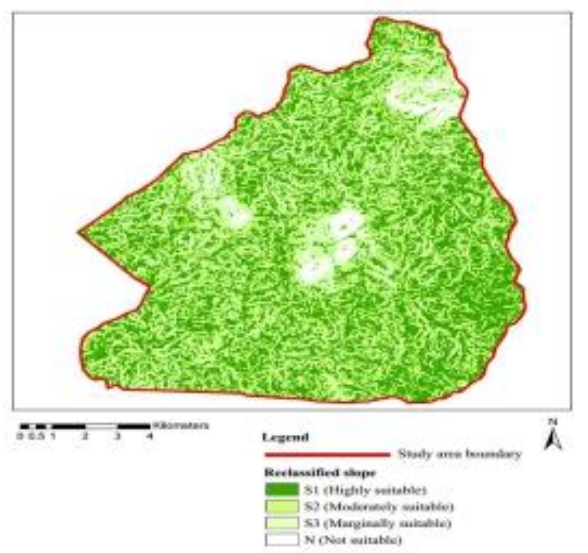

(d) Reclassified Slope

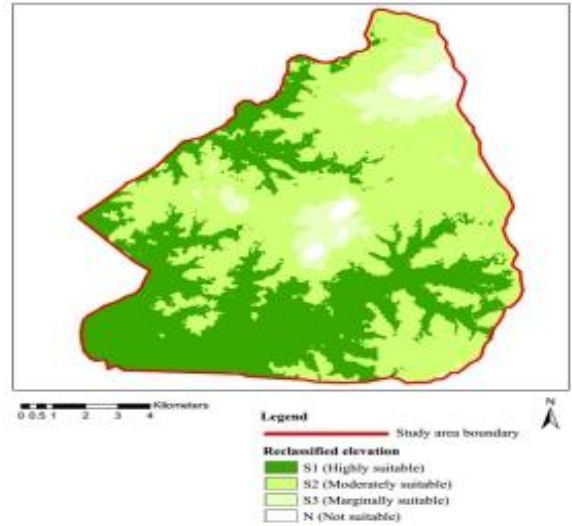

(f) Reclassified Elevation

Figure 4. (a-f) Reclassified land suitability criteria 
Land Suitability Evaluation for Cassava Production Using Integral Value Ranked Fuzzy AHP and GIS Techniques

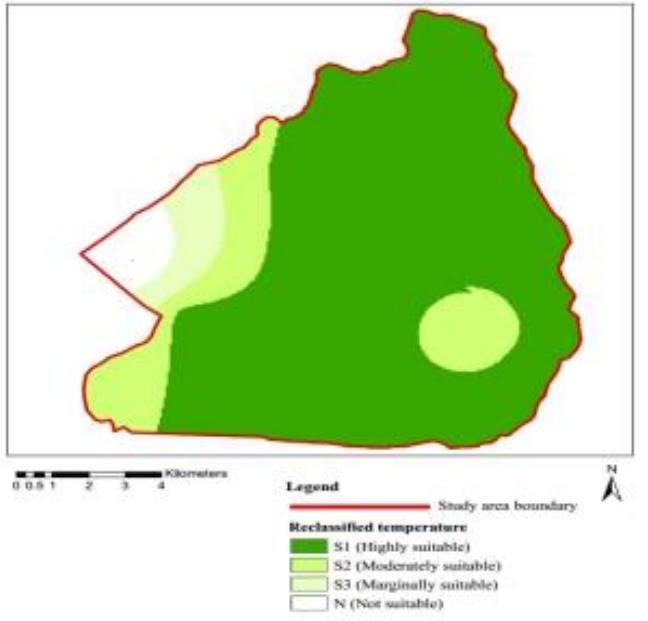

(g) Reclassified Temperature

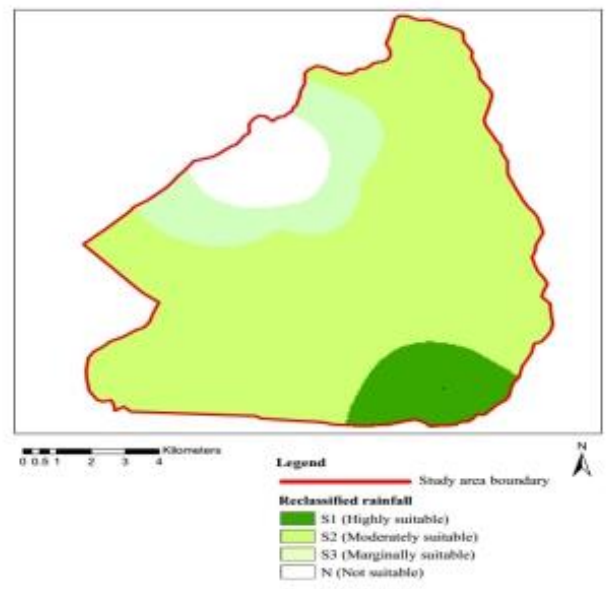

(i) Reclassified Rainfall

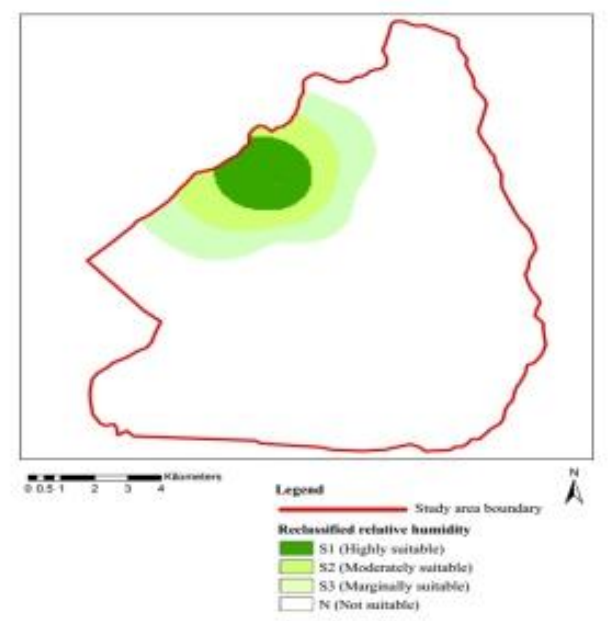

(h) Reclassified Relative humidity

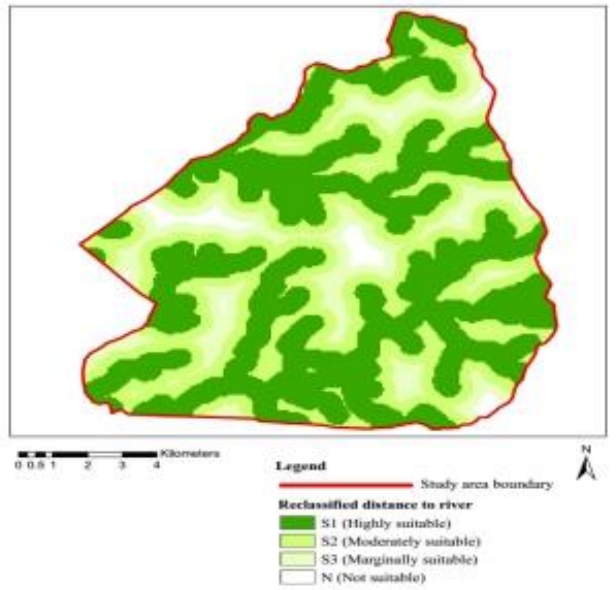

(j) Reclassified Distance from river

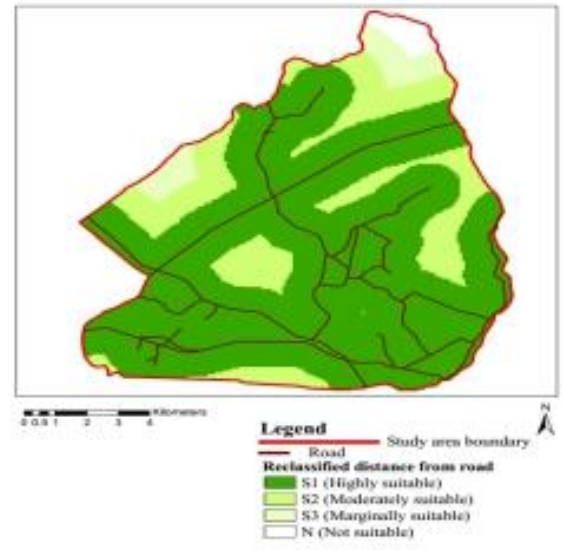

(k) Reclassified road

Figure 5. (g-k) Reclassified land suitability criteria 


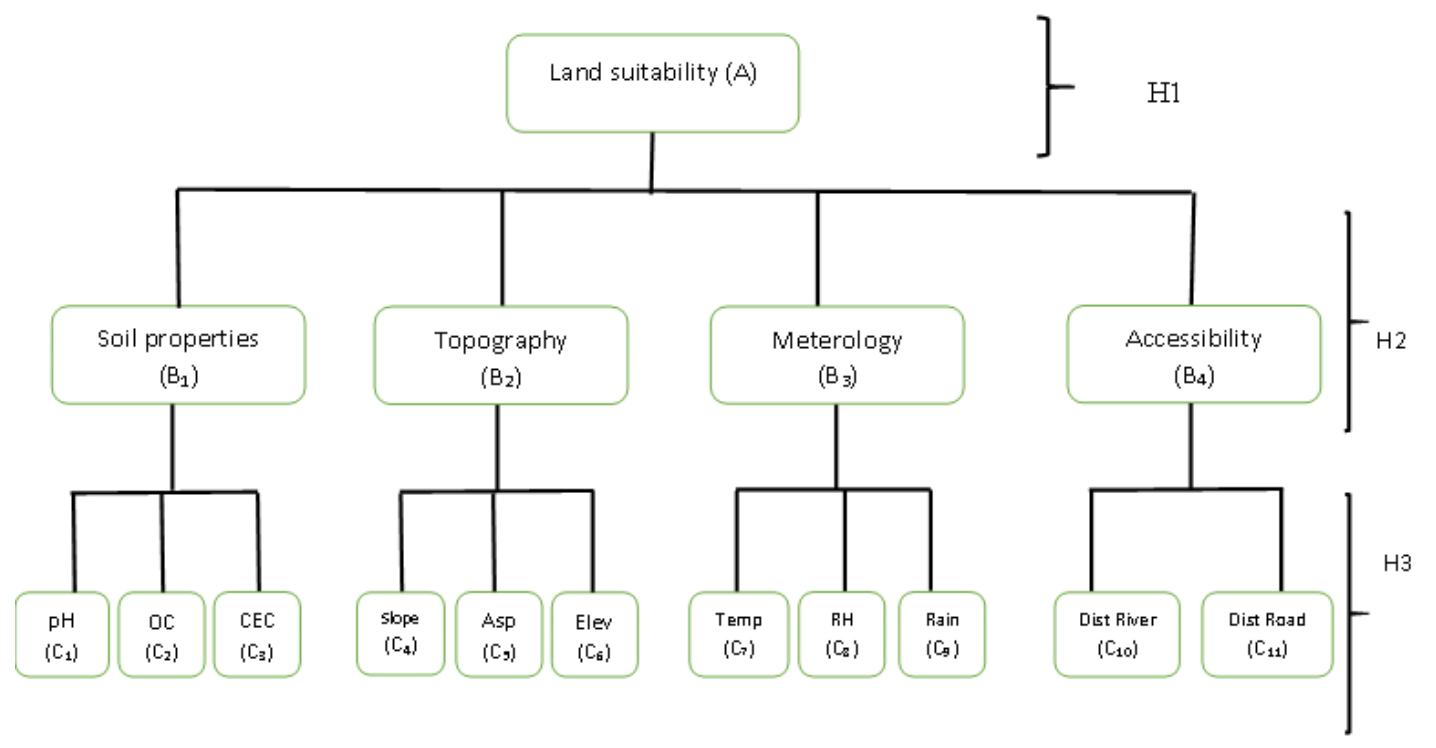

Figure 6. Hierarchical structure

\subsection{Fuzzy sets}

A fuzzy set can be described as a class of objects within an array of membership grades [36]. Linguistic variables are represented by membership functions, valued in the real unit interval which translates the indistinctness and fuzziness of human thought associated with the proposed problem. In this study, the Triangular Fuzzy Numbers (TFNs) were used to represent the fuzzy comparative importance. A TFN is graphically shown in [Figure 7] and can be described as:

$$
\mu_{\widetilde{N}}(x)=\left\{\begin{array}{cc}
\frac{x-l}{m-l}, & l \leq x \leq m \\
\frac{u-x}{u-m}, & m \leq x \leq u \\
0, & \text { otherwise }
\end{array}\right.
$$

where parameters $l, m$, and $u$ respectively denote the smallest possible value, the most promising value, and the largest possible value that describes a fuzzy event.

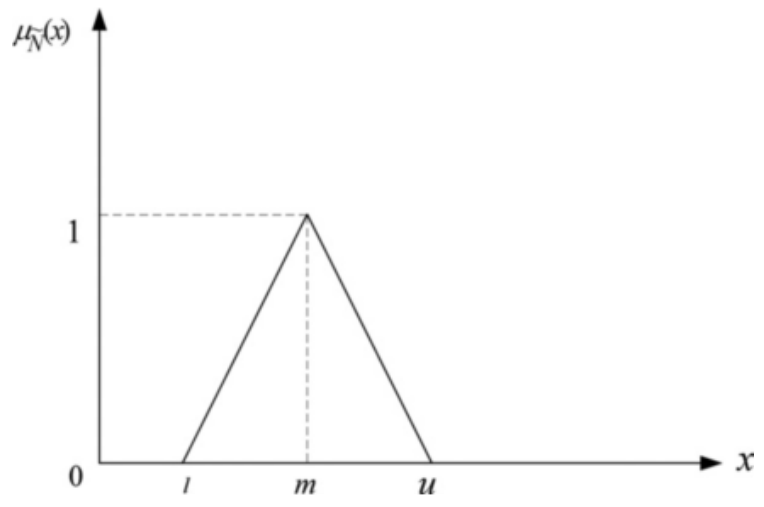

Figure 7. Triangular fuzzy number (source: [37]) 
Fuzzy TFN'S, linguistic variables, and membership functions utilized in this project were those proposed in the works of [21] and [38]. They are shown in [Table 2].

Table 2. TFNs, linguistic variables, and membership functions (Source: [38])

\begin{tabular}{|c|c|c|c|c|c|}
\hline $\begin{array}{l}\text { Saaty's } \\
\text { scale of } \\
\text { relative } \\
\text { importance }\end{array}$ & Definition & Membership function & Domain & $\begin{array}{c}\text { TFNs scale } \\
\qquad(1, \mathrm{~m}, \mathrm{u})\end{array}$ & $\begin{array}{l}\text { Linquistic } \\
\text { variables }\end{array}$ \\
\hline & Just equal & & & $\begin{array}{c}(1.0,1.0, \\
1.0)\end{array}$ & Just equal \\
\hline 1 & $\begin{array}{c}\text { Equal } \\
\text { importance }\end{array}$ & $\mu_{A}(x)=(3-x) /(3-1)$ & $1 \leqslant x \leqslant 3$ & $(1.0,1.0,3.0)$ & $\begin{array}{c}\text { Least } \\
\text { Importance } \\
\end{array}$ \\
\hline \multirow[b]{2}{*}{3} & \multirow{2}{*}{$\begin{array}{l}\text { Moderate } \\
\text { importance of } \\
\text { one over } \\
\text { another }\end{array}$} & $\mu_{A}(x)=(x-1) /(3-1)$ & $1 \leqslant x \leqslant 3$ & \multirow[b]{2}{*}{$(1.0,3.0,5.0)$} & \multirow{2}{*}{$\begin{array}{l}\text { Moderate } \\
\text { Importance }\end{array}$} \\
\hline & & $\mu_{A}(x)=(5-x) /(5-1)$ & $3 \leqslant x \leqslant 5$ & & \\
\hline \multirow[b]{2}{*}{5} & \multirow{2}{*}{$\begin{array}{l}\text { Essential or } \\
\text { strong } \\
\text { importance }\end{array}$} & $\mu_{A}(x)=(x-3) /(5-3)$ & $3 \leqslant x \leqslant 5$ & \multirow[b]{2}{*}{$(3.0,5.0,7.0)$} & \multirow[b]{2}{*}{$\begin{array}{l}\text { Essential } \\
\text { Importance }\end{array}$} \\
\hline & & $\mu_{A}(x)=(7-x) /(7-5)$ & $5 \leqslant x \leqslant 7$ & & \\
\hline \multirow[t]{2}{*}{7} & \multirow[t]{2}{*}{$\begin{array}{l}\text { Demonstrated } \\
\text { importance }\end{array}$} & $\mu_{A}(x)=(x-5) /(7-5)$ & $5 \leqslant x \leqslant 7$ & \multirow[t]{2}{*}{$(5.0,7.0,9.0)$} & \multirow[t]{2}{*}{$\begin{array}{l}\text { Demonstrated } \\
\text { Importance }\end{array}$} \\
\hline & & $\mu_{A}(x)=(9-x) /(9-7)$ & $7 \leqslant x \leqslant 9$ & & \\
\hline 9 & $\begin{array}{c}\text { Extreme } \\
\text { importance }\end{array}$ & $\mu_{A}(x)=(x-7) /(9-7)$ & $7 \leqslant x \leqslant 9$ & $(7.0,9.0,9.0)$ & $\begin{array}{c}\text { Extreme } \\
\text { Importance }\end{array}$ \\
\hline
\end{tabular}

\subsection{Weight's determination}

Steps used for obtaining weights are outlined as follow:

Get pairwise comparison matrix using Fuzzy AHP.

Compute weights for each of the pairwise comparison matrices in (a) using an improved integral value ranked Fuzzy AHP model as proposed by [24].

Compute the final weights using a hierarchical process as described by [21]. Each of the steps is detailed in sections 2.6.1, 2.6.2, and 2.6.3.

\subsubsection{Pairwise comparison matrix using Fuzzy-AHP}

The main steps for developing a pairwise comparison matrix using fuzzy AHP are as follows:

(1) Structuring decision hierarchy. As in AHP, the first step is to break down the complex decision-making problem into a hierarchical structure.

(2) Develop pairwise fuzzy comparison matrices. For example, consider a prioritization problem at a level with $\mathrm{n}$ elements, where pairwise comparison judgments are designated by fuzzy triangular numbers $\tilde{a}_{i j}=\left(l_{i j}, m_{i j}, u_{i j}\right)$. As in the conventional AHP, each set of comparisons for a level requires $n(n-1) / 2$ judgments, which are further used to build a positive fuzzy reciprocal comparison matrix $\tilde{A}=\left\{\tilde{a}_{i j}\right\}$ such that:

$$
\tilde{A}=\left\{\tilde{a}_{i j}\right\}=\left[\begin{array}{ccc}
a_{11} & \cdots & a_{1 n} \\
\vdots & \ddots & \vdots \\
a_{n 1} & \cdots & a_{n n}
\end{array}\right]
$$

The pairwise comparison matrix used in this study was obtained using steps 1 and 2 . 


\subsubsection{Compute weights for the pairwise comparison matrix using an improved integral value ranked fuzzy AHP model}

The improved integral value ranked Fuzzy AHP method as proposed by [24] and highlighted by equation 3 was used to compute the weights of the criteria.

$$
S_{T}^{a}\left(A_{i}\right)=\alpha S_{R}\left(A_{i}\right)+(1-\alpha) S_{L}\left(A_{i}\right)
$$

where parameters $S_{R}\left(A_{i}\right)$ and $S_{L}\left(A_{i}\right)$ denote the right integral value of the fuzzy number $A_{i}$ and the left integral of fuzzy number $A_{i}$ respectively, $S_{T}^{a}\left(A_{i}\right)$ is the total integral value, $\alpha$ is the index of optimism which denotes the degree of optimism for decision-makers. If $\alpha$ tends towards 1 in $[0,1]$, the decision-makers are more optimistic, if $\alpha$ tends towards 0 in $[0,1]$, they are more pessimistic $[23 ; 26] . \alpha$ of 0.7 was used.

The normalized importance weight vector $W=\left(w_{1}, w_{2}, \ldots, w_{n}\right)$ of the fuzzy judgment matrix $A$ is determined using equation 4 :

$$
w_{i}=\frac{S_{T}^{a}\left(A_{i}\right)}{\sum_{i=1}^{n} S_{T}^{a}\left(A_{i}\right)} i=1,2, \ldots, n
$$

where $w$ is a non-fuzzy number.

The weight for each factor in the hierarch using equations 3 and 4 is shown in the last column of [Tables 3] to [Table 7].

(1) Calculating the fuzzy consistency ratio

Comparison $\mathrm{z}$ relies on subjective judgment which might lead to an illogical result with bias hence an evaluation is needed [39]. To determine if consistency was sustained in assigning weights a ratio known as Fuzzy Consistency Ratio (FCR) was calculated. The method used was that proposed by [40], which is based on the preference ratio concept. The preference ratio of all comparisons made for the criteria at each hierarchical level [Tables 3 to 7] was lower than $10 \%(0.1)$ which shows that the consistency of pairwise comparison is acceptable.

(2) Pairwise comparison matrix and weight

Pairwise comparison matrix and weights generated using the improved integral value ranked Fuzzy AHP method is shown in [Tables 3-7]. Fuzzy Consistency Ratio (FCR) was used in determining the consistency of generated weights.

Table 3. Pairwise comparison matrix A-B $\mathrm{B}_{1-4}$

\begin{tabular}{|c|c|c|c|c|c|}
\hline $\mathrm{A}$ & $\mathrm{B}_{1}$ & $\mathrm{~B}_{2}$ & $\mathrm{~B}_{3}$ & $\mathrm{~B}_{4}$ & $\mathrm{~W}$ (weight) \\
\hline $\mathrm{B}_{1}$ & $1,1,1$ & $1,3,5$ & $3,5,7$ & $5,7,9$ & 0.4987 \\
\hline $\mathrm{B}_{2}$ & $0.2,0.33,1$ & $1,1,1$ & $1,3,5$ & $3,5,7$ & 0.2839 \\
\hline $\mathrm{B}_{3}$ & $0.14,0.2,0.33$ & $0.2,0.33,1$ & 111 & $3,5,7$ & 0.1612 \\
\hline $\mathrm{B}_{4}$ & $0.2,0.14,0.33$ & $0.14,0.2,0.33$ & $0.14,0.2,0.33$ & 111 & 0.0562 \\
\hline
\end{tabular}

Table 4. Pairwise comparison matrix $\mathrm{B} 1-\mathrm{C}_{1-3}$

\begin{tabular}{|c|c|c|c|c|}
\hline $\mathrm{B}_{1}$ & $\mathrm{C}_{1}$ & $\mathrm{C}_{2}$ & $\mathrm{C}_{3}$ & $\mathrm{~W}$ (weight) \\
\hline $\mathrm{C}_{1}$ & $1,1,1$ & $1,3,5$ & $3,5,7$ & 0.5601 \\
\hline $\mathrm{C}_{2}$ & $0.2,0.33,1$ & 111 & $3,5,7$ & 0.3475 \\
\hline
\end{tabular}




\begin{tabular}{|c|c|c|c|c|}
\hline $\mathrm{C}_{3}$ & $0.14,0.2,0.33$ & $0.14,0.2,0.33$ & 111 & 0.0925 \\
\hline
\end{tabular}

Table 5. Pairwise comparison matrix $\mathrm{B}_{2}-\mathrm{C}_{4-6}$

\begin{tabular}{|c|c|c|c|c|}
\hline $\mathrm{B}_{2}$ & $\mathrm{C}_{4}$ & $\mathrm{C}_{5}$ & $\mathrm{C}_{6}$ & $\mathrm{~W}$ (weight) \\
\hline $\mathrm{C}_{4}$ & $1,1,1$ & $1,3,5$ & $3,5,7$ & 0.5601 \\
\hline $\mathrm{C}_{5}$ & $0.2,0.33,1$ & 111 & $3,5,7$ & 0.3475 \\
\hline $\mathrm{C}_{6}$ & $0.14,0.2,0.33$ & $0.14,0.2,0.33$ & 111 & 0.0925 \\
\hline
\end{tabular}

$B_{2}=$ Topography; $C_{4}=$ Slope; $C_{5}=$ Aspect $; C_{6}=$ Elevation. $F C R=0.0379$

Table 6. Pairwise comparison matrix $\mathrm{B}_{3}-\mathrm{C}_{7-9}$

\begin{tabular}{|c|c|c|c|c|}
\hline $\mathrm{B}_{3}$ & $\mathrm{C}_{7}$ & $\mathrm{C}_{8}$ & $\mathrm{C}_{9}$ & $\mathrm{~W}$ (weight) \\
\hline $\mathrm{C}_{7}$ & $1,1,1$ & $1,3,5$ & $3,5,7$ & 0.5601 \\
\hline $\mathrm{C}_{8}$ & $0.2,0.33,1$ & 111 & $3,5,7$ & 0.3475 \\
\hline $\mathrm{C}_{9}$ & $0.14,0.2,0.33$ & $0.14,0.2,0.33$ & 111 & 0.0925 \\
\hline
\end{tabular}

$B_{3}=$ Climate $C_{7}=$ Temp $; C_{8}=R H ; C_{9}=$ Rain. $F C R=0.0379$

Table 7. Pairwise comparison matrix $\mathrm{B}_{4}-\mathrm{C}_{10-11}$

\begin{tabular}{|c|c|c|c|}
\hline $\mathrm{B}_{4}$ & $\mathrm{C}_{10}$ & $\mathrm{C}_{11}$ & $\mathrm{~W}$ (weight) \\
\hline $\mathrm{C}_{10}$ & 111 & $1,3,5$ & 0.7948 \\
\hline $\mathrm{C}_{11}$ & $0.2,0.33,1$ & 111 & 0.2052 \\
\hline
\end{tabular}

$B_{4}=$ Accessibility; $C_{10}=$ Dist. from rivers; $C_{11}=$ Dist. from roads

\subsubsection{Compute the final weights of each input layer using a hierarchical process}

The weight of every latest factor in Table 8 to the main objective of the hierarchy (A) was calculated by normalizing the weight of each factor in [Table 3] to [Table 7]. This was done by multiplying the weight of a factor in the lower level by that of the elements in the upper level as long as they are directly related in the hierarchical structure. For example, to get the final weight of the slope input layer represented by $\mathrm{C}_{1}$ in the hierarchy, the following formulae were used

$$
\text { Finalweightof } C_{1}=\text { Weightof } C_{1} \text { to } B_{1} * \text { Weightof } B_{1} \text { toobjectiveA }
$$

This was done for all the input layers and the results are shown in [Table 8].

Table 8. Hierarchical structure and final weight

\begin{tabular}{|c|c|c|c|c|}
\hline Goal A & Hierarchy B & Hierarchy C & Final weights & Name \\
\hline $\mathrm{A}$ & $\mathrm{B}_{1}$ & $\mathrm{C}_{1}$ & 0.27932 & $\mathrm{pH}$ \\
\hline & & $\mathrm{C}_{2}$ & 0.17329 & OC \\
\hline & & $\mathrm{C}_{3}$ & 0.04612 & CEC \\
\hline & $\mathrm{B}_{2}$ & $\mathrm{C}_{4}$ & 0.15901 & Slope \\
\hline
\end{tabular}




\begin{tabular}{|c|c|c|c|c|}
\hline & & $\mathrm{C}_{5}$ & 0.09865 & Aspect \\
\hline & & $\mathrm{C}_{6}$ & 0.02626 & Elevation \\
\hline & $\mathrm{B}_{3}$ & $\mathrm{C}_{7}$ & 0.09028 & Temp \\
\hline & & $\mathrm{C}_{8}$ & 0.05601 & $\mathrm{RH}$ \\
\hline & & $\mathrm{C}_{9}$ & 0.01491 & Rain \\
\hline & $\mathrm{B}_{4}$ & $\mathrm{C}_{10}$ & 0.04466 & Dist. from River \\
\hline & & $\mathrm{C}_{11}$ & 0.01153 & Dist. from major roads \\
\hline
\end{tabular}

\subsection{Aggregation}

After assigning the associated weights to each input layer, an aggregation stage was commenced to combine the information from the various factors and constraints. The weighted linear combination (WLC) was chosen as the method of aggregation as shown in equation 6 . This approach multiplies each standardized factor map by its factor weight then sums the results

$$
s=\sum W_{i} x_{i}
$$

$s=$ suitability, $W_{i}=$ weight of factor $i$, and $x_{i}=$ factor $i$

This was done on a pixel-by-pixel basis and yielded a suitability map with the same range of values as the standardized factor maps that were used. The outcome of equation 6 is shown in [Figure 6] which is a map of land suitability for cassava cultivation across the study area.

\section{Results and discussion}

Cassava is an important income generating and food security crop, especially in subSaharan Africa. In this work, an improved integral value ranked Fuzzy AHP and GIS based MCDM system was deployed to evaluate and map land suitability for cassava production in the study area.

A hierarchical structure comprising of three factors and 11 sub-factors was used. The weights for the factors were determined by first creating a FAHP pairwise comparison matrix, thereafter the weights for each of the pairwise comparison matrix was obtained using the improved integral value ranked fuzzy AHP approach and the final weights were computed using a hierarchical process. This methodology provides a new and effective scientific method for land suitability assessment for cassava production. The main advantage of the model is the ability to derive optimum weights for the input factors thus enhancing accuracy. Furthermore, this model enables us to deal with the subjective uncertainty in agricultural land evaluation. The fuzzy consistency ratio was below $10 \%(0.1)$ for the various comparison matrices. This shows that the consistency of the pairwise comparison is acceptable.

The outcome of the aggregation using equation (13) was reclassified into four classes using the standard deviation classification method (this method shows how much a feature deviates from the mean). The reclassified output is shown in figure 6 which shows the land suitability distribution for cassava production across the study area. The distribution of the land suitability analysis for the study area from table 9 showed that $40 \%$ of the land $(56 \mathrm{sq}$ $\mathrm{km}$ ) was highly suitable (this is consistent with the fact that the study area is an agrarian area where a large portion of the area is suitable for cassava production), 36\% of the land (51 sq $\mathrm{km}$ ) was moderately suitable, $20 \%$ of the land (28 sq $\mathrm{km})$ was marginally suitable and $4 \%$ of 
the land (5 sq $\mathrm{km})$ was not suitable. In addition, the land areas most suitable for cassava production were areas where the soil had high $\mathrm{pH}$ and organic carbon values.

\subsection{Classified land use land cover map}

Land use land cover (LULC) analysis of the study area was carried out. Landsat 8 image of the study area captured in December 2016 with a resolution of $30 \mathrm{~m}$ was used for the LULC classification. Three classes were used for the classification namely water body, settlement, and vegetal covers. [Figure 7] shows the LULC map of the study area. [Table 10] shows the LULC class distribution across the study area.

\subsection{Comparison between suitability map and LULC map}

From [Table 10] it can be seen that the vast majority of land in the study area was the vegetal cover (77.6\%), these areas are either already existing farmlands or potential farmlands. Comparing [Figure 6] with [Figure 7] it can be seen that the bulk of the vegetal cover lies within the region of highly suitable and moderately suitable areas for cassava cultivation. This shows that the area has the potential for large scale cultivation of cassava. Fieldwork carried out shows that the bulk of cassava farms in the study area were small scale farms and mainly at a subsistence farming scale. Large commercial scale farms would be suitable in the study area. Figure 8 shows the overlay of settlement over the land suitability distribution for the study area. [Figure 8] shows that the bulk of the highly suitable areas are outside the settlement class. Furthermore, from [Table 10] it can be seen that settlements occupy just $31.1 \mathrm{sq} \mathrm{km}$ or $22.2 \%$ of the study area as the bulk of the study area falls within the vegetal cover class (77.6). This shows that the study area will be highly suitable for large scale commercial cassava farming. Even within the areas covered by settlement small scale cassava cultivation could be carried out by the sides alongside vegetable gardens which are common within the study area.

\subsection{Recommendations}

It should be noted that increasing the $\mathrm{pH}$ and organic content of the soil especially in areas classified as moderately and marginally suitable has the potential of increasing soil suitability for cassava farming within the study area. These two factors were the major determinant of soil suitability for cassava cultivation in the study area as these two factors $(\mathrm{pH}$ and organic content of the soil) had the highest weight as shown in [Table 8]. This is thus recommended to further increase cassava production in the study area.

\section{Conclusion}

This research established an approach to assess land suitability and map out the most suitable areas for cassava production within the study area using the improved integral value ranked fuzzy AHP and GIS based MCDM techniques. This is intending to ensure sustainable and improved cassava production within the study area. The multicriteria decision analysis was done for suitability assessment using eleven criteria: $\mathrm{pH}$, organic carbon, cation exchange capacity, slope, aspect, elevation, temperature, relative humidity, rain, distance from the river, and distance from the road. The land suitability analysis for the study area showed that $40 \%$ of the land ( $56 \mathrm{sq} \mathrm{km}$ ) was highly suitable for cassava production. Findings from this study also showed that $\mathrm{pH}$ and organic content of the soil were the major determinants of soil suitability for cassava cultivation in the study area. This research 
provides an effective spatial multi-criteria decision-making method for optimum and sustainable cassava production in the study area. In addition, it has the potential to be used in study zones with similar conditions. We recommend that the technique be utilized on a regional/national scale and further develop into an app that will readily provide needed realtime information to intended farmers and decision-makers.

Table 9. Suitable area for cassava production in the study area

\begin{tabular}{|c|c|c|}
\hline Suitability Class & Area (sq km) & Percentage area (\%) \\
\hline Highly suitable & 56 & $30 \%$ \\
\hline Moderately suitable & 51 & $20 \%$ \\
\hline Marginally suitable & 28 & $4 \%$ \\
\hline Not suitable & 5 & 100 \\
\hline Total & 140 & $20 \%$ \\
\hline
\end{tabular}

Table 10. LULC class distribution

\begin{tabular}{|c|c|c|}
\hline LULC Class & Area $(\mathrm{sq} \mathrm{km})$ & Percentage area (\%) \\
\hline Settlement & 31.1 & 22.2 \\
\hline Waterbody & 0.3 & 0.2 \\
\hline Vegetal cover & 108.6 & 77.6 \\
\hline Total & 140 & 100 \\
\hline
\end{tabular}

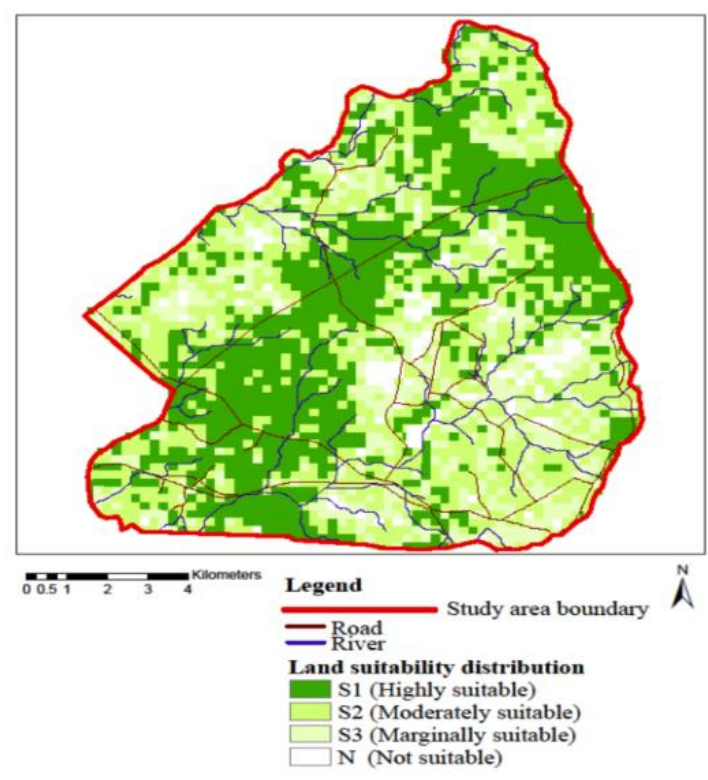

Figure 8. Land suitability distribution for cassava production 


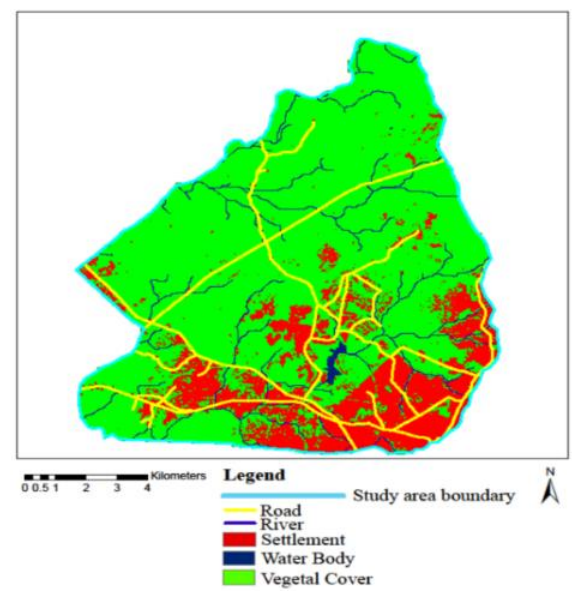

Figure 9. Land use Land cover of the study area

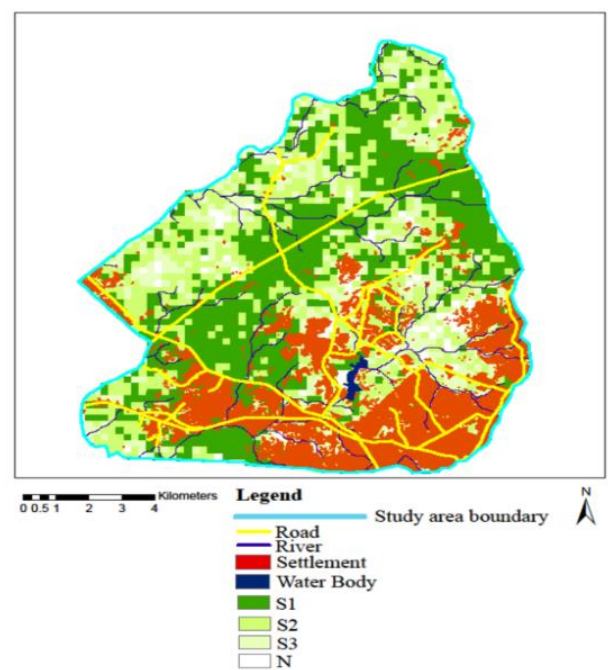

Figure 10. Settlement overlaid over the land suitability distribution for the study area.

\section{Acknowledgments}

This research did not receive any specific grant from funding agencies in the public, commercial, or not-for-profit sectors.

\section{References}

[1] Agus, F., Sholeh, R., Hatta, H. R., Munawwarah, and T., "Fuzzy analytical hierarchy process for land suitability analysis compared to analytical hierarchy process," In 1st International Conference on Science and Technology for Sustainability, Oct., (2014)

[2] Rossiter and D. G., "A theoretical framework for land evaluation," Geoderma, vol.72, no.3, pp.165-190, (1996)

[3] Baja, S., Arif, S., Neswati, and R., "Developing a user-friendly decision tool for agricultural land use allocation at a regional scale," Mod. Appl. Sci., (2017) 
[4] Nurmiaty, N., Baja, and S., "Using fuzzy set approaches in a raster GIS for land suitability assessment at a regional scale: Case study in Maros Region,” Indonesia. Modern Applied Science, vol.8, no.3, pp.115-125, (2014)

[5] Habibie, M. I., Noguchi, R., Shusuke, M., Ahamed, and T., "Land suitability analysis for maize production in Indonesia using satellite remote sensing and GIS-based multicriteria decision support system," GeoJournal, pp.1-31, (2019)

[6] Biratu, G. K., Elias, E., and Ntawuruhunga, P., "Soil fertility status of cassava fields treated by integrated application of manure and NPK fertilizer in Zambia," Environmental Systems Research, vol.8, no.1, p.3, (2019)

[7] Alamu, E. O., Ntawuruhunga, P., Chibwe, T., Mukuka, I., and Chiona, M. "Evaluation of cassava processing and utilization at household level in Zambia," Food Security, vol.11, no.1, pp.141-150, (2019)

[8] Guo, Y., "Closing yield gap of cassava for food security in West Africa," Nature Food, vol.1, no.6, pp.325325, (2020)

[9] Jiang, D., Wang, Q., Ding, F., Fu, J., and Hao, M., "Potential marginal land resources of cassava worldwide: A data-driven analysis,” Renewable and Sustainable Energy Reviews, pp.167-173, (2019)

[10] Nguyen, T. H., Williams, S., and Paustian, K., "Impact of ecosystem carbon stock change on greenhouse gas emissions and carbon payback periods of cassava-based ethanol in Vietnam. Biomass and bioenergy," 100, pp.126-137, (2017)

[11] Heumann, B., Walsh, J., and McDaniel P, "Assessing the application of a geographic presence-only model for land suitability mapping,” Ecological Inform, vol.6, no.5, pp.257-269, (2011)

[12] Laskar, A., "Integrating GIS and multicriteria decision making techniques for land resource planning," Netherlands: ITC, Dec., (2003)

[13] Din, G. Y., and Yunusova, A. B., "Using AHP for evaluation of criteria for agro-industrial projects," International Journal of Horticulture and Agriculture, vol.1, no.1, (2016)

[14] Qureshi, M. R. N., Singh, R. K., and Hasan, M. A., "Decision support model to select crop pattern for sustainable agricultural practices using fuzzy MCDM. Environment,” Development and Sustainability, vol.20, no.2, pp.641-659, (2018)

[15] Kahsay, A., Haile, M., Gebresamuel, G., and Mohammed, M., "Land suitability analysis for sorghum crop production in northern semi-arid Ethiopia: Application of GIS-based fuzzy AHP approach," Cogent Food \& Agriculture, vol.4, no.1, pp.1507184, (2018)

[16] Pamučar, D., Gigović, L., Bajić, Z., and Janošević, M., "Location selection for wind farms using GIS multicriteria hybrid model: An approach based on fuzzy and rough numbers,” Sustainability, vol.9, no.8, pp.1315, (2017)

[17] Tahri, M., Maanan, M., Maanan, M., Bouksim, H., and Hakdaoui, M., "Using fuzzy analytic hierarchy process multi-criteria and automatic computation to analyze coastal vulnerability," Progress in Physical Geography, vol.41, no.3, pp.268-285, (2017)

[18] Akbari, M., Neamatollahi, E., \& Neamatollahi, P., "Evaluating land suitability for spatial planning in arid regions of eastern Iran using fuzzy logic and multi-criteria analysis," Ecological indicators, pp.98, pp.587598, (2019)

[19] Purnamasari, R. A., Ahamed, T., and Noguchi, R., "Land suitability assessment for cassava production in Indonesia using GIS, remote sensing and multi-criteria analysis," Asia-Pacific Journal of Regional Science, vol.2, no.1, pp.1-3, (2019)

[20] Ahmed, F., and Kilic, K., "Modification to fuzzy extent analysis method and its performance analysis. In industrial engineering and systems management (IESM)," International Conference on IEEE, pp.435-438, Oct., (2015)

[21] Chang, D.Y. Applications of the extent analysis method on fuzzy AHP. Eur. J. Oper. Res., pp.95, pp.649-655, (1996) 
[22] Mikhailov, L., "Deriving priorities from fuzzy pairwise comparison judgments," Fuzzy Sets and Systems, pp.134, pp.365-385, (2003)

[23] Liou, T. S., and Wang, M. J. J., "Ranking fuzzy numbers with integral value. Fuzzy sets and systems," vol.50, no.3, pp.247-255, (1992)

[24] Vincent, F. Y., and Dat, L. Q., “An improved ranking method for fuzzy numbers with integral values. Applied Soft Computing,” pp.14, pp.603-608, (2014).

[25] Ruan, J., Shi, P., Lim, C., and Wang, X., "Relief supplies allocation and optimization by interval and fuzzy number approaches,” Information Sciences, pp.303, pp.15-32, (2015)

[26] Kabir, G. and Sumi, R. S., "Integrating fuzzy analytic hierarchy process with PROMETHEE method for total quality management consultant selection," Production \& Manufacturing Research, vol.2, no.1, pp.380-399, (2014)

[27] Wang, Q., Wang, H., and Qi, Z., "An application of nonlinear fuzzy analytic hierarchy process in safety evaluation of coal mine," Safety Science, pp.86, pp.78-87, (2016)

[28] Diallo, M. D., Wood, S. A., Diallo, A., Mahatma-Saleh, M., Ndiaye, O., Tine, A. K., and Guisse, A., "Soil suitability for the production of rice, groundnut, and cassava in the peri-urban Niayes zone," Senegal. Soil and Tillage Research, pp.155, pp. 412-420, (2016)

[29] Heng, T., de Jesus, J. M., Heuvelink, G. B., Gonzalez, M. R., Kilibarda, M., Blagotić, A., and Guevara, M., “A SoilGrids250m: Global gridded soil information based on machine learning," PLoS one, vol.12, no.2, (2017)

[30] Ahukaemere, C. M., \& Obasi, N. S., "Potentials of soils derived from Asu river group and Asata Nkporo shale for arable crop production in Ebonyi State," Nigeria. Bulgarian Journal of Soil Science, vol.3, no.1, pp.48-62, (2018)

[31] Gbadegesin, A. S., Abua, M. A., \& Atu, J. E., "Variation in soil properties on cassava production in the coastal area of Southern cross river State,” Nigeria. Journal of Geography and Geology, vol.3, no.1, pp.94, (2011)

[32] Purnamasari, R. A., Noguchi, R., and Ahamed, T., "Land suitability assessments for yield prediction of cassava using geospatial fuzzy expert systems and remote sensing," Computers and Electronics in Agriculture, pp.166, (2019)

[33] Wezel, A., Steinmüller, N., and Friederichsen, J. R., "Slope position effects on soil fertility and crop productivity and implications for soil conservation in upland northwest Vietnam. Agriculture," Ecosystems \& Environment, vol.91, no.1-3, pp.113-126, (2002)

[34] Schneider, D. P., Deser, C., Fasullo, J., \& Trenberth, K. E., "Climate data guide spurs discovery and understanding," Eos, Transactions American Geophysical Union, vol.94, no.13, pp.121-122, (2013)

[35] Odjugo P., "The impact of tillage systems on soil microclimate, growth and yield of cassava (Manihot utilisima) in Midwestern Nigeria," African Journal of Agricultural Research, vol.3, no.3, pp.225-233, (2008)

[36] Zadeh, L. A., "Fuzzy sets," Information and Control, vol.8, no.3, pp.338-353, (1965)

[37] Javanbarg, M., Scawthorn, C., Kiyono, J., and Shahbodaghkhan, B., "Fuzzy AHP-based multicriteria decision making systems using particle swarm optimization," Expert systems with application, vol.39, pp.960-966, (2012)

[38] Tsiko, R., and Haile, T.S., "Integrating geographical information systems, fuzzy logic and analytical hierarchy process in modelling optimum sites for locating water reservoirs," A Case Study of the Debub District in Eritrea. Water, vol.3, pp.254-290, (2011) DOI: 10.3390/w3010254.

[39] Xinyi D, "Dam site selection using an integrated method of AHP and GIS for decision making support in Bortala," Northwest China. Unpublished MSc Thesis, Lund University, Lund, Sweden, Sept., (2016)

[40] Modarres, M., Sadi-Nezhad, S., and Arabi, F., "Fuzzy analytical hierarchy process using preference ratio: A case study for selecting management short course in a business school," International Journal of Industrial Engineering Computations, vol.1, no.2, pp.173-184, (2010) 